\title{
Identidade e alteridade em Gabriel e a montanha e Sem teto nem lei
}

\author{
Maria Ignês Carlos Magno \\ Doutora em Ciências da Comunicação pela Escola de Comunicações e Artes da Universidade \\ de São Paulo (ECA-USP) e professora do Programa de Pós-Graduação em Comunicação da \\ Universidade Anhembi Morumbi. \\ E-mail: unsigster@gmail.com
}

André Gustavo de Paula Eduardo.

Doutorando em Comunicação pela Universidade Anhembi Morumbi e mestre em Comunicação pela Universidade Estadual Paulista (Unesp).

E-mail: agpe13@yahoo.com.br

Resumo: Esta resenha objetiva comentar os filmes Gabriel e a montanha, de Fellipe Barbosa, e Sem teto nem lei, de Agnès Varda, e promover uma reflexão sobre os conceitos de identidade e alteridade por meio da comparação dos filmes - que contêm aspectos narrativos semelhantes, já que os protagonistas de um e outro são viajantes; porém, a viagem e o caminhar trazem sentidos bastante distintos, os quais interessam a esta resenha.

Palavras-chave: cinema brasileiro; Gabriel e a montanha; identidade; alteridade; Sem teto nem lei.
Abstract: This review aims to comment on the movies Gabriel e a montanha, directed by Fellipe Barbosa, and Vagabond, directed by Agnès Varda, and promote a reflection about the concepts of identity and otherness by comparing the movies - which contain similar narrative aspects, since the main characters of both movies are travelers; however, the path and the journey convey quite distinct significances, which are of interest for this review.

Keywords: Brazilian cinema; Gabriel and the mountain; identity; otherness; Vagabond. 


\section{FELLIPE BARBOSA E O JOGO DAS APARÊNCIAS}

É provável que o nome de Fellipe Barbosa tenha de fato alcançado a repercussão que hoje tem após o sucesso de Gabriel e a montanha (2017), sobretudo entre a crítica de cinema francesa. Após o lançamento de Domingo (2018), o sucesso do cineasta deve prosseguir; mas vale desde já relembrar sua trajetória, a fim de mostrar sua afinidade por determinados temas e uma maneira, por assim dizer, singular de filmá-los. A amizade e o apreço com os personagens costumam surgir dotados de uma conflituosa ambivalência, um jogo de aparências no qual o diretor parece "abandonar" seus personagens a fim de permitir ao máximo que fiquem próximos ao juízo dos espectadores. Mas é claro que isso não o inocenta, nem seu olhar nem sua câmera, e podemos concluir que esse jogo é o centro do processo criativo de Barbosa, ou seja, permitir alguma dose de distanciamento a fim de estudar os movimentos de seus personagens.

Percebe-se que Barbosa gosta de se inspirar em figuras próximas, pessoas queridas, amigos - já foi assim com seu curta Beijo de sal (2007), baseado no encontro com um amigo. Seu primeiro longa-metragem, Laura (2011), é um documentário sobre uma amiga - brasileira nascida na Argentina - que vive em Nova York e cuja principal ocupação é "caçar" celebridades, infiltrar-se em festas e conhecer atores ou cantores famosos. No que poderia soar como um desfile de futilidades, o interesse do filme se debruça sobre a banalidade do gesto e a falta de qualquer aspecto especial sobre este mundo. Laura, de certa maneira, é estudada com a curiosidade antropológica de Barbosa. Já Casa grande (2014) traz uma família de classe média alta da Barra da Tijuca (RJ), arruinada financeiramente, mas que não mede esforços para manter o que resta das aparências antigas. Embora mal tenham dinheiro para o transporte do filho à escola, tentam manter os luxos especiais e a empregada confinada em seu quartinho.

No universo de Fellipe Barbosa, os personagens se movimentam em um jogo de simulacros e simulações, ou seja, um universo de aparências, que inclusive podem parecer, por assim dizer, reais - algo que Baudrillard ${ }^{1}$ definiria como aquele mundo no qual a referência desapareceu, dando lugar ao recurso da simulação e da volatilidade. Uma vez que não há mais a "curvatura do real, nem a da verdade", estaríamos numa era de simulação, com a "liquidação de todos os referenciais" e sua consequente "ressurreição artificial no sistema de signos"2. Observemos que o uso da expressão liquidação por parte de Baudrillard nada tem de fortuito, em intimidade com a liquidez da modernidade evocada por Bauman ${ }^{3}$.

Em Laura, Casa grande e Gabriel e a montanha, fingir ou parecer importam mais do que ser, ou ainda: se confundem com ser- seja em Laura, com a heroína determinada a preencher sua vida se misturando a celebridades, como se, misticamente, adquirisse as características mágicas dos famosos que conhece; seja na casa grande que só se sustenta enquanto imenso espaço, dotado de conforto e de uma jacuzzi, num esforço de manter a aparência de ser rico, algo mais importante do que ter a riqueza de fato; ou em Gabriel, que concebe uma África repleta de clichês de cartoons e interage com ela enquanto estereótipo, num processo em que a alteridade cede espaço à vaidade e a seus preconceitos pessoais. 
O foco destas páginas reside em Gabriel e a montanha, na reconstrução da jornada do protagonista - inspirado em um amigo seu, cuja rota e destino trágico de fato ocorreram - e em sua relação com os habitantes que conhece e com o espaço que visita, estudado aqui à luz de autores afeitos à compreensão da pós-modernidade, tais como Baudrillard ${ }^{4}$ e Bauman ${ }^{5}$ (mas também sob a óptica de outras contribuições, como a noção de "sociedade de desempenho" trazida por Byung-Chul $\mathrm{Han}^{6}$ ). A comparação com Sem teto nem lei, longa-metragem de Agnès Varda de 1985, se dá como algo quase inevitável, não apenas pelas diversas semelhanças com o filme de Fellipe Barbosa, mas porque o processo de comparação permite desnudar as percepções tão distintas dos protagonistas de ambos os filmes.

\section{GABRIEL E O MUNDO AO SEU REDOR}

Gabriel e a montanha principia com o capítulo "Quênia"7 Lá, Gabriel ${ }^{8}$ é chamado mzungu, "homem branco". "Homem simples e sociável”, descreve o amigo queniano, que depois batizaria o filho com o nome de Gabriel. Tudo nele, no começo, inspira simpatia. Brinca com crianças. Ganha uma espada e o respeito dos amigos do povo masai. E desde já se veste com roupas caricatas, tribais, a espada e o cajado. O visual aqui já configura um elemento de simulacro: é como se a roupa o transformasse num masai, num queniano tribal. Logo ficará claro que a indumentária serve apenas a ele, para participar, na condição de turista (embora se considere "viajante"), daquilo que julga ser o dia a dia no local. Uma espécie de alteridade forçada. Gabriel não parece ver complexidade ou nuances nos masai, que formariam uma unidade exótica. Pretende viver num mundo distinto, não naquele afeito ao hiperespaço pós-moderno ${ }^{9}$ que contamina todo lugar. Afirma ter encontrado uma "alma da África”, como se houvesse tamanha pureza e homogeneidade em um continente tão grande, lugar pertencente às "culturas híbridas do pós-colonialismo"10. Em mundo contemporâneo marcado por êxodos e refúgios, Gabriel é o viajante que escolhe, como turista, sempre à vontade: não precisa de uma senha de adaptação, como o imigrante, mas antes escolhe assumir uma espécie de identidade temporária, essa alteridade descrita anteriormente, mas com um olhar por vezes autoritário, como que superior aos demais. Um amigo do Quênia o "batiza" como Lemayan, "o mais abençoado", apelido que descreve nas cartas à família: "tô muito roots". Acredita viajar de forma "sustentável" e doa parte de seus recursos à gente local, que o acolhe.

Não demora muito para Gabriel (ou Lemayan) mostrar outras facetas. Sob a veste tribal há um caráter autoritário e competitivo. Sobe o Kilimanjaro e se apressa a tirar fotos, como o sujeito de desempenho, na definição de Byung-Chul $\mathrm{Han}^{11}$. Quer sempre superar a natureza, pouco importando as adversidades. Tem lesões nos olhos por não querer usar óculos escuros em meio à neve, já anunciando a tragédia futura. A fotografia surge como personagem fundamental em Gabriel e a montanha, pois é outro elemento de simulacro que reproduz
4. BAUDRILLARD, op. cit.

5. BAUMAN, op. cit.

6. HAN, Byung-Chul. Sociedade do cansaço Petrópolis: Vozes, 2017.

7. GABRIEL e a montanha. Direção: Fellipe Barbosa. Intérpretes: João Pedro Zappa, Caroline Abras, Leonard Siampala, John Goodluck, Alex Alembe, Rashidi Athuman, Luke Mpata, Rhosinah Sekeleti et al. Rio de Janeiro: Gamarosa Filmes; TV Zero, 2017. (131 min), son., color.

8. Interpretado por João Pedro Zappa. A namorada de Gabriel, Cristina, é vivida por Carolina Abras.

9. Em referência à expressão de Fredric Jameson: GUPTA, Akhil; FERGUSON, James. Mais além da "cultura": espaço, identidade e política da diferença. In: ARANTES, Antonio (org.). O espaço da diferença Campinas: Papirus, 2000 p. 31

10. BAUDRILLARD, op. cit. p. 33.

11. HAN, op. cit. 
uma memória de sucesso, de bom desempenho. Alcançar o cume só faz sentido se houver uma máquina fotográfica por perto. Ser e parecer têm as fronteiras erodidas, são uma só substância: sem as fotos, numa sociedade competitiva, o esforço teria sido nulo, ou apenas uma experiência pessoal.

Já no segundo capítulo, "Tanzânia”, entra em cena a namorada, Cristina, que viaja à África. Gabriel lhe explica o vestuário exótico - é a única figura com vestes tribais no aeroporto - e o sentido da espada que ganhou, sempre como comprovação de status. Começam as rusgas com um dos guias, pois Gabriel quer ver gnus ${ }^{12}$, o que estava fora do roteiro: "estou pagando". Gabriel e Cristina almoçam com um casal, moça dinamarquesa e rapaz africano, que não consegue entrar na Europa - ao contrário de Gabriel, que se regozija: "A Dinamarca é meu segundo país". Daí, "Lemayan” já saiu de cena, e emerge uma figura notavelmente ególatra. Quando percebe que o guia se confundiu na hora da cobrança, ensaia uma agressão física. Terminam por ver os gnus, com um clima péssimo. Diminui Cristina todo o tempo, pois esteve em universidade e colégios "tops". Afirma "odiar" os EUA, embora esteja às vésperas de se mudar para Los Angeles. E explica sua presença no continente africano porque quer "trabalhar com pessoas que realmente precisam" - nasceu e vive no Brasil, mas não experienciou a pobreza em seu país e, como turista, fetichiza a miséria.

No capítulo "Zâmbia", passa horas realizando o download de suas fotos. Por conta disso Cristina perde o passeio com elefantes, e ele perde o bungee jump. No quarto e último capítulo, "Malawi”, Cristina já se foi. Com as mãos machucadas, Gabriel insiste em subir a montanha Mulanjie, embora o guia alerte que não há tempo. Pouco importa. Gabriel usa sandálias e não tem equipamento apropriado. Novamente, a fotografia surge em momento chave, quando, no meio do caminho, ele pede ao guia para fotografá-lo enquanto pula de uma altura considerável em um lago. Como o guia errou o tempo da foto, Gabriel terá que pular outras vezes. A experiência não vale nada sem o registro dela. Em certo sentido, a experiência de se atirar de um rochedo na água vale menos que o registro fotográfico que será exibido em redes sociais, marca típica de uma sociedade de desempenho, na qual todos os aspectos, do trabalho ao lazer, devem culminar em processo de autocobrança e busca incessante por certa noção de sucesso. Gabriel, em alguma medida, é o sujeito narcisista da contemporaneidade e, portanto, busca menos a experiência em si do que o autojúbilo; a ideia de alteridade para ele não funciona. Ou talvez funcione o que chamamos anteriormente de alteridade forçada, uma simpatia que também se afirma enquanto simulacro.

A falta de relação com o outro provoca acima de tudo uma crise de gratificação. A gratificação como reconhecimento pressupõe a instância do outro ou do terceiro. O narcisista não está afeito a experiências, ele quer vivenciar a si mesmo [...]. A coação de desempenho força-o a produzir cada vez mais. Assim, jamais alcança um ponto de repouso da gratificação. Vive constantemente num sentimento de carência e de culpa. E visto que, em última instância, está concorrendo consigo mesmo, procura superar a si mesmo até sucumbir ${ }^{13}$. 
Daí decorre, segundo Han, o fato de o sujeito na sociedade de desempenho tender ao esgotamento, burnout. "O sujeito de desempenho se realiza na morte. Realizar-se e autodestruir-se, aqui, coincidem"14. Após acusar o guia de "preguiçoso", termina por seguir viagem sozinho, até se perder e morrer, provavelmente de hipotermia. Reside no filme de Fellipe Barbosa uma teleologia moralista, e não uma suposta "neutralidade" do olhar: Gabriel morrerá e é o único culpado por isso: apressado, mal equipado, desconfiado, arrogante, presunçoso, autoritário, diminui os guias, "preguiçosos", e menospreza a natureza local.

Durante sua jornada, Gabriel busca a todo momento uma aldeia que não existe, um africano tribal e caricato cujo modelo se inspira nos clichês da mídia, e haverá estranhamento quando não encontrar os pressupostos caricaturais. Beatriz Sarlo ${ }^{15}$ aponta uma tendência, mesmo entre culturas camponesas, a esse processo de contaminação. As culturas por definição são híbridas, distintas de um longínquo hermetismo que caracterizaria as tribos isoladas, os povos com pouco contato entre si. Gabriel, moldado num mundo pós-moderno, não compreende o alcance desse processo e sua expressão, em qualquer parte do mundo à qual vá. Se as culturas populares "não escutam mais, como voz externa privilegiada, as autoridades tradicionais" ${ }^{\prime 6}$, nosso herói não entende isso. Procura um mundo que não existe mais e tem a certeza pedante de tê-lo encontrado.

As identidades tradicionais eram estáveis ao longo do tempo e obedeciam a forças centrípetas que operavam tanto sobre os traços originais quanto sobre os elementos e valores impostos pela dominação econômica e simbólica. Hoje, as identidades atravessam processos de "balcanização"; vivem um presente desestabilizado pela desaparição de certezas tradicionais e pela erosão da memória [...]. Essa trama de vínculos cara a cara, em que princípios de coesão pré-modernos fundavam autoridades tradicionais, dispersou-se para sempre. As velhas estratégias já não podem soldar as bordas das novas diferenças ${ }^{17}$.

Gabriel, portanto, idealiza o homem africano, como se esquecesse do mundo radicalmente interconectado em que vive. Sua limitada compreensão do processo faz com que continue boa parte de sua viagem a se vestir como um guerreiro tribal, carregando a espada que ganhou de presente e destoando, assim, dos demais moradores locais, vestidos com jeans e roupas menos exóticas. Os africanos são, pois, objetos para ele.

Da mesma forma argumenta, para a namorada, que está na África para conhecer a pobreza de perto. Ex-aluno da Pontifícia Universidade Católica do Rio de Janeiro (PUC-RJ), orgulhoso de ter estudado nas "melhores escolas do Brasil", afirma querer "fazer algo" pelos pobres globais - em algum momento terá lhe ocorrido que a pobreza está em toda parte em seu próprio país? Gabriel responde a um mecanismo de clichês no qual o africano, além de tribal, seria uma espécie de miserável por vocação. À sua maneira, atribui-se uma missão, uma espécie de fardo do homem branco particular. Seu olhar é colonial e sua ajuda é um gesto de piedade para com pessoas que, segundo sua visão, o admiram pelas esmolas que dá. Anuncia ter penetrado na "alma da África", mas basicamente se movimenta no espaço compreendido por Akhil Gupta e
14. Ibidem, p. 83-86.

15. SARLO, Beatriz. Cenas da vida pós-moderna: intelectuais, arte e videocultura na Argentina. Rio de Janeiro: Editora UFRJ, 2006. p. 101.

16. Ibidem, p. 102 17. Ibidem, p. 105. 
James Ferguson como pertencentes "às culturas híbridas do pós-colonialismo" - nesse hiperespaço pós-moderno, já mencionado anteriormente.

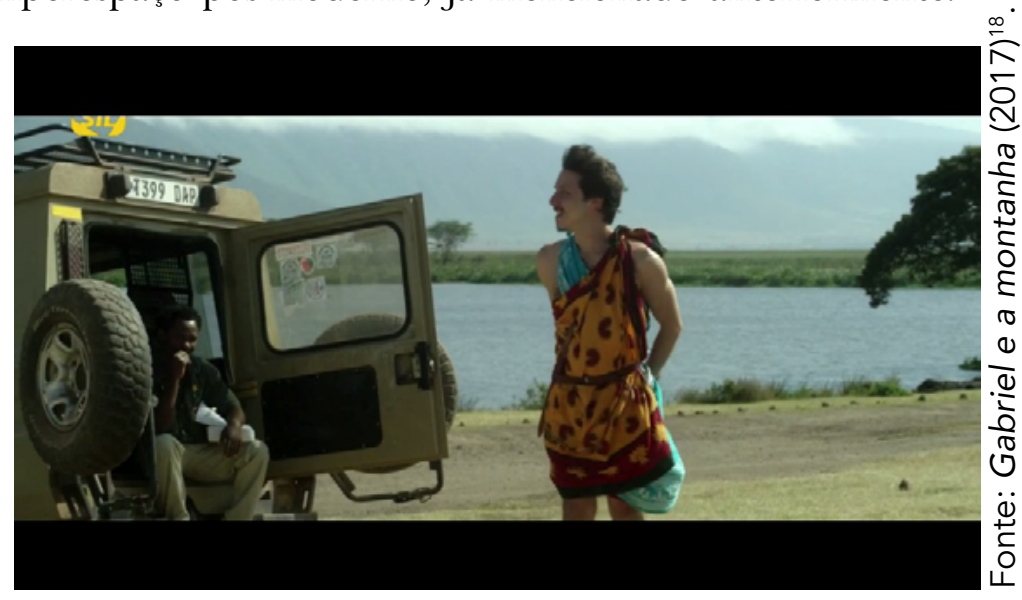

Imagem 1: Gabriel e sua indumentária tribal

Angustiado com a incerteza de realizar ou não sua pós-graduação em Los Angeles, Gabriel busca um mundo que idealiza e fantasia, reafirmando em suas cartas e conversas uma espécie de "dom", seu talento para a compreensão dos mais necessitados, como se fosse um ente superior - se não é, ao menos olha para todos com ares de superioridade. Menino rico do Rio de Janeiro, é a típica personalidade que se considera interessante: o homem dotado de capital cultural e, portanto, de um caleidoscópio que o permite enxergar o que pobres mortais e mortais pobres não veem. Seu capital será em primeiro lugar o dinheiro de sua família; mas este será sempre encoberto por seu capital cultural, conforme observação de Jessé Souza ${ }^{19}$ : seus bens reconhecidos e admirados são bens imateriais, como "prestígio, reconhecimento, respeito, charme ou beleza"; dinheiro, beleza, cultura e conhecimento são percebidos como algo exterior ao sujeito, sendo necessário "desenvolver estratégias que transformem o dinheiro em expressão de algo inato e interno ao sujeito": Gabriel é interessante porque teria em si mesmo uma "distinção inata e não comprada com dinheiro". Se realiza tantas viagens, fala idiomas distintos e conhece países, é por mero "acaso feliz" e não por possuir dinheiro ${ }^{20}$.

\section{O TURISTA E O VAGABUNDO}

Houve quem enxergasse semelhanças entre Gabriel e a montanha e Sem teto nem lei (Sans toit ni loi, 1985), de Agnès Varda. E não seria incompreensível se houvesse alguma acusação de plágio por parte de Fellipe Barbosa devido não apenas à semelhança das histórias, mas a determinados expedientes narrativos

18. GABRIEL..., op. cit.

19. SOUZA, Jessé. A elite do atraso: da escravidão à Lava Jato. Rio de Janeiro: Leya, 2017. p. 93-94.

20. Ibidem, p. 93-94. escolhidos em um e outro filme, que se mostram muito parecidos. Logo de início, em ambos, encontramos trabalhadores pobres - na África e na França, que é ambiente de Sem teto nem lei - e começa toda a especulação acerca das mortes, com diversos depoimentos em voice over. O esquema de realizar o filme como um grande flashback tem espaço nos dois filmes, com ligeira diferença: 
em Gabriel, ouvimos as lembranças sobre o protagonista após a partida do mochileiro brasileiro. Em Sem teto, há mais fragmentação e vaivéns temporais, mas o mecanismo é o mesmo.

No entanto, mais que as semelhanças, interessam aqui as diferenças entre os protagonistas, figuras diversas cujas jornadas possuem propósitos radicalmente distintos.

Mona $^{21}$ é o nome da jovem encontrada morta logo de início. Assim como Gabriel, está para cima e pra baixo com uma mochila, porém não sai de seu país, a França. E jamais deixa claro por que está viajando: afinal, sequer poderíamos chamar seu percurso de "viagem", pois temos uma figura altamente ensimesmada que simplesmente vive como andarilha. Ao contrário de Gabriel, não celebra grandes feitos, não tem recursos, fala pouco, não tem destino. Dorme ao relento com uma barraca velha. Acampa no frio, eventualmente se relaciona com alguém que conhece na estrada, numa estadia em algum canto ou durante uma carona - esses personagens trarão a memória da moça, sem, no entanto, conseguir decifrá-la. Mona nunca está disposta ao trabalho, embora se empregue vez ou outra para obter abrigo, comida e algum dinheiro. Quase um Bartleby ambulante, que "prefere não fazer". Se Gabriel está imerso no desempenho apontado por Byung-Chul Han, Mona é o oposto: é como o Bartleby de Herman Melville, que "não suporta o imperativo pós-moderno, de começar a abandonar o eu" "22. Mona, à semelhança de Bartleby, é uma "figura sem referência para consigo mesmo ou algo outro" e sente-se mal com o "excesso de positividade ou de possibilidade" ${ }^{23}$, no limiar da aparência entre uma "garota comum" e uma maltrapilha. Não tem planos nem rumo, apenas vaga. Em dado momento, torna-se amiga de um imigrante muçulmano que, com seus conterrâneos, surgem como párias do país. É uma dica importante, pois o vagabundo seria o pária da modernidade, segundo Bauman ${ }^{24}$. Em alguma medida, Mona é uma espécie de apátrida por vocação. Vaga pelas estradas, como uma nômade sem povo, solitária, em uma "versão mais radical", sem aspiração de encontrar uma pátria, mas feliz justamente por não ter uma ${ }^{25}$. Gabriel, ainda que não goste da expressão, é turista - ao contrário da andarilha Mona em sua vagabundagem.

Em primeiro lugar, o equilíbrio entre factores de "repulsa" e "atracção" inclina-se pesadamente, no caso do vagabundo, para o lado da "repulsa", mas, para o da "atracção", no caso do turista. O turista desloca-se com um propósito (ou assim pensa deslocar-se). Os seus movimentos fazem-se antes do mais "a fim de". [...] O turista nasceu em nós da insatisfação incessante e do desejo de contraste. Nunca nos convencemos de ter experimentado as coisas com intensidade bastante; temos sempre uma consciência surda que nos diz que as nossas experiências poderiam ter sido melhores ${ }^{26}$.

Como turista, Gabriel procura "uma sensação rejuvenescedora e tonificante, que mistura um vago aroma de perigo com uma impressão de salvação" ${ }^{27}$. "No mundo do turista, o estranho está domesticado, já não apavora, e o horror faz parte de um pacote comprado com garantias. $\mathrm{O}$ mundo parece portanto infinitamente confortável, infinitamente obediente aos desejos e fantasias do turista" ${ }^{28}$. Mona está na
21. Interpretada por Sandrine Bonnaire.

22. HAN, op. cit., p. 62.

23. Ibidem, p. 62-63.

24. BAUMAN, op. cit., p. 100.

25. CANCLINI, Néstor. O mundo inteiro como lugar estranho. São Paulo: Edusp, 2016. p. 69.

26. BAUMAN, op. cit., p. 101.

27. Ibidem, p. 102.

28. Ibidem, p. 102. 
categoria do vagabundo, ainda conforme Bauman, essa "praga da modernidade" 29. Ao contrário do turista ou de um nômade, o vagabundo escapa ao controle.

O que tornava o vagabundo tão assustador era a sua aparente liberdade de se deslocar e de escapar assim à rede de controlo anterior, de base local. Pior ainda, os movimentos do vagabundo eram imprevisíveis: ao contrário do peregrino ou, sob o aspecto que aqui nos importa, do nômada, o vagabundo não tem destino marcado. Não se sabe para onde irá a seguir, porque ele próprio o não sabe ou isso não o preocupa muito ${ }^{30}$.

Por fim, Gabriel se perde no ambiente selvagem e morre; Mona está eternamente perdida e deslocada na civilização. O primeiro, turista, acredita viver uma jornada espiritual, alimentada pelo contato com culturas diferentes, por conta do apelido sagrado que ganhou, além de sua espada e seu cajado tribais. Mona é a viajante indesejável, cujo propósito interno bem poderia ser, digamos, uma espécie de "viagem espiritual". Sem teto nem lei não traz pistas, pois nunca sabemos quem de fato é a estranha viajante. Desse mistério advém uma beleza mística: "Estrangeiro aqui como em toda parte", como dizem os versos de Fernando Pessoa.

29. BAUMAN, op. cit., p. 99

30. Ibidem, p. 100.

31. GABRIEL..., op. cit.

32. SEM TETO nem lei. Direção e roteiro: Agnès Varda. Intérpretes: Sandrine Bonnaire, Macha Méril, Stéphane Freiss et al. Paris: Ciné Tamaris, 1985 DCP (105 min), son., color. $35 \mathrm{~mm}$. Título original: Sans toit ni loi.

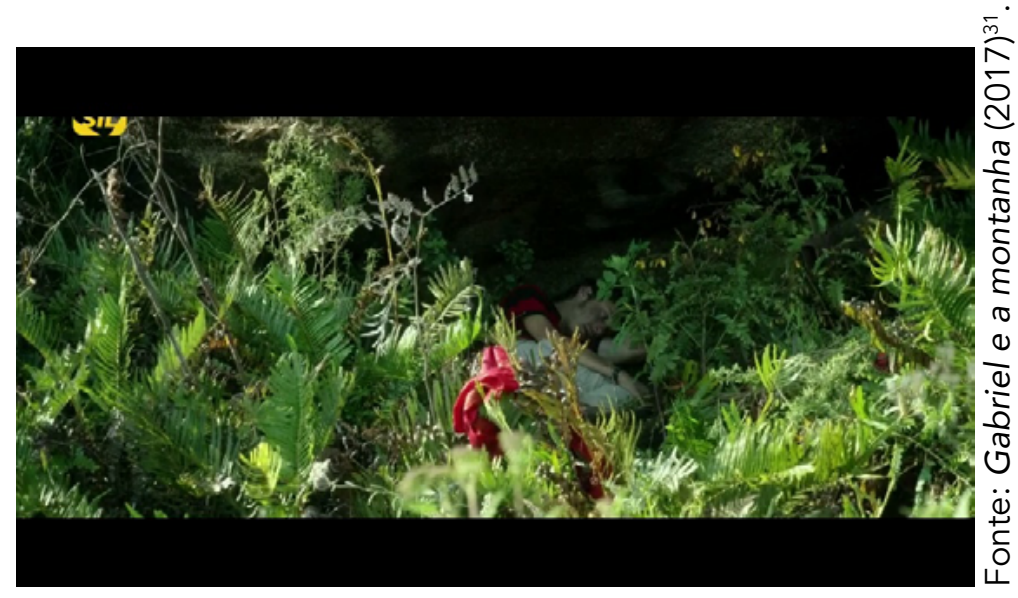

Imagem 2: Gabriel, encontrado morto, próximo a um rochedo

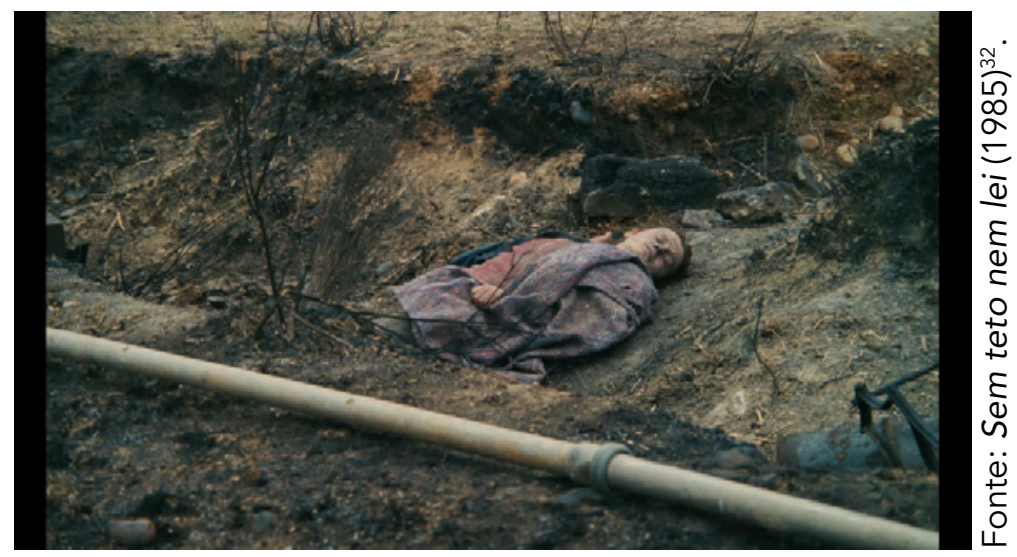

Imagem 3: Mona, morta em uma vala, após tentar fugir do frio 


\section{DESFECHO}

As errâncias da personagem de Agnès Varda possuem a marca da inadaptabilidade. Ela foge, apenas foge. Terá na morte obtido uma fuga perfeita? Gabriel, ao contrário, porta-se como desbravador e possui algo de autoritário e colonial. Tanto Gabriel e a montanha quanto Sem teto nem lei permitem uma série de reflexões acerca do homem contemporâneo, bem como do problema da identidade e a da alteridade. Sabemos que Gabriel pratica turismo, embora com verniz de iluminação espiritual. Mona é a viajante sem rumo num mundo hostil, sem laços, família ou amigos: assume a radicalidade da peregrinação, na qual a moradia fixa é o próprio ato de peregrinar. É uma pária, sem dúvida: não pertence ao mundo do consumo nem tampouco à sociedade de desempenho, fenômeno recente - como se sua jornada, ainda que pareça inócua, revelasse o sentido maior de preservar sua liberdade, seu valor supremo. Participa tangencialmente do mundo, vivendo dos restos. Com encaixá-la num mundo de simulacros? Mona parece avessa a isso, pois não tem obrigações ou "máscaras" sociais. A vagabundagem existe como reafirmação radical da individualidade, mesmo que às custas da misantropia ou até mesmo da falta de proteção social que isso implica (não tem dinheiro, vive de rápidos trabalhos miseráveis, dorme ao relento, sofre com o frio, é abusada sexualmente em algum momento do filme). Mas não está insatisfeita com essa vida. Atua, assim, como antípoda de Gabriel, que conhece todos os continentes mas penetra pouco na essência deles. É curioso que o diretor e roteirista Fellipe Barbosa dedique o filme ao amigo Gabriel, pintado aqui como infantil e autoritário. Talvez seu intento fosse o de não o eximir de suas falhas, que são, em alguma medida, as falhas de todo ser humano.

\section{REFERÊNCIAS BIBLIOGRÁFICAS}

BAUDRILLARD, Jean. Simulacros e simulação. Lisboa: Relógio d'Água, 1991.

BAUMAN, Zygmunt. A vida fragmentada: ensaios sobre a moral pós-moderna. Lisboa: Relógio d'Água, 1995.

CANCLINI, Néstor. O mundo inteiro como lugar estranho. São Paulo: Edusp, 2016.

GABRIEL e a montanha. Direção: Fellipe Barbosa. Intérpretes: João Pedro Zappa, Caroline Abras, Leonard Siampala, John Goodluck, Alex Alembe, Rashidi Athuman, Luke Mpata, Rhosinah Sekeleti et al. Rio de Janeiro: Gamarosa Filmes; TV Zero, 2017. (131 min), son., color.

GUPTA, Akhil; FERGUSON, James. Mais além da "cultura”: espaço, identidade e política da diferença. In: ARANTES, Antonio (org.). O espaço da diferença. Campinas: Papirus, 2000.

HAN, Byung-Chul. Sociedade do cansaço. Petrópolis: Vozes, 2017. 
comunicação \& educação • Ano XXIV • número 1 • jan/jun 2019

SARLO, Beatriz. Cenas da vida pós-moderna: intelectuais, arte e videocultura na Argentina. Rio de Janeiro: Editora UFRJ, 2006.

SEM TETO nem lei. Direção e roteiro: Agnès Varda. Intérpretes: Sandrine Bonnaire, Macha Méril, Stéphane Freiss et al. Paris: Ciné Tamaris, 1985. DCP (105 min), son., color., $35 \mathrm{~mm}$. Título original: Sans toit ni loi.

SOUZA, Jessé. A elite do atraso: da escravidão à Lava Jato. Rio de Janeiro: Leya, 2017. 